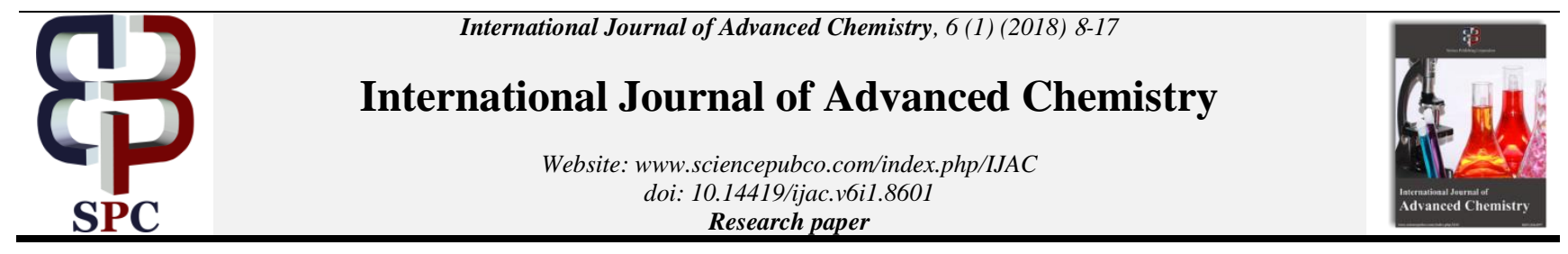

\title{
Synthesis, spectral characterization (FT-IR and NMR) and DFT (Conformational analysis, molecular structure, HOMO-LUMO, UV-vis, NLO) computational studies on 2,2'-((1E,1'E)-phenazine-2,3 dilbis(azanylylidene))bis(methanyly- lidene))diphenol
}

\author{
A. Prabhakaran', E. Dhinesh Kumar², D. Rajaraman³, M. Arockia Doss* 3 \\ ${ }^{1}$ Department of Chemistry, CK College of Engineering and Technology, Cuddalore, 607003, India \\ ${ }^{2}$ Department of Chemistry, Annamalai University, Annamalainagar 608 002, India \\ ${ }^{3}$ Department of Chemistry, St. Joseph University, Nagaland 797 115, India \\ *Corresponding author E-mail:arockia91@gmail.com
}

\begin{abstract}
A new Schiff base was synthesized for the first time by the phenazine-2,3-diamine and 2-hydroxy benzaldedye in ethanol (1:1). The structure of Schiff bases was experimentally characterized by using UV-vis, IR, ${ }^{1} \mathrm{H}$ NMR and ${ }^{13} \mathrm{C}$ NMR spectroscopic methods. Further, the synthesized compound was subjected to DFT for better understanding of the molecular architecture and optoelectronic properties. The optimized geometric parameters supported the available experimental values. The Mulliken and MEP analyses are utilized to identify reactive sites of title molecule. The energetic behaviors of compound 3 in hexane, chloroform, methanol solvents and gas phase were examined using by time-dependent DFT (TD-DFT) method by applying the polarizable continuum model (PCM). The calculated $\Delta \mathrm{E}$ energies exposed that charge transfer takes place within the molecule. In addition to the polarizability and hyperpolarizability have been calculated which exhibit that compounds possess non-linear optical nature.
\end{abstract}

Keywords: Schiff Base; DFT; HOMO-LUMO; Mulliken Charge; MEP.

\section{Introduction}

Schiff bases have drawn the chemists' attention due to the effortlessness of preparation. Schiff bases have the azomethine group $(-\mathrm{RC}=\mathrm{N}-)$ and are regularly formed by the condensation of a primary amine with an active carbonyl compound. Schiff bases have gained importance in pharmaceutical field owing to the most versatile organic synthetic intermediates and also showing a broad range of biological activities, like antituberculosis, anticancer, analgesic and anti-inflammatory, anticonvulsant antibacterial and antifungal activities [Li et al.2003; Amr et al.2008; Said et al. 2009; Abdel-Hafez et al. 2009; Mohamed et al. 2010; Al-Omar et al. 2010; Al-Salahi et al. 2010; Moustafa et al. 2010; Sayed et al. 2010; Ghozlan et al. 2011; Yousif et al. 2011; Hanan et al. 2017]. These Schiff bases are good intermediates for the synthesis of many heterocyclic ring systems like thiazolidinone, azetidinones etc. [Yousif et al. 2011]. Schiff's bases are important compounds owing to their wide range of industrial applications [ $\mathrm{Li}$ et al. 2003]. Schiff's bases are used in the photostabilization of polymers against photodegradation by ultraviolet radiation [Yousif et al. 2011]. Regardless of this fact, studies regarding the investigation of their molecular structure and their electronic structure by computational techniques are lacking in the chemical literature
[NevinSüleymanoğlu et al. 2017; Nasser MohammedHosny et al. 2017]. The use of computational techniques is becoming increasingly common thought all the fields of science. The main purpose of this work is to take advantage of quantum mechanics to support and complement experimental data. Although, several spectral investigations were reported for Schiff base, yet none have provided any quantitative interpretation or assignments of the observed spectra, nor it relates these spectral findings to the electronic structure of Schiff base. This work will reveal an additional quantitative chemical knowledge of the formation, bioactivity, geometry and electronic properties. The present work reports the results of a systematic study of the geometrical and electronic structure, electrostatic potential surfaces, molecular hyperpolarizability and thermodyanamic parameters based on their density functional theory computations.

\subsection{Materials and methods}

All chemicals were commercially purchased and without prior purification they were used. Melting points were found in open capillary tube and were uncorrected. Elemental analyses were carried out with Variomicro V2.2.0 CHN analyser. FT-IR spectrum of title compound was recorded on a Shimadzu FT-IR spectrophotometer in the range $400-4000 \mathrm{~cm}^{-1}$ using the $\mathrm{KBr}$ pellets. 
The ${ }^{1} \mathrm{H}$ NMR spectra were gathered on a BRUKER AVANCE III $400 \mathrm{MHz}$ NMR spectrometer using DMSO- $d_{6}$ as solvent.

Synthesis of 2, 2'-((1E, 1'E)-phenazine-2, 3 diylbis(azanylylidene))bis(methanylylidene))diphenol(3)

Both the mixtures phenazine-2, 3-diamine $1(0.15 \mathrm{~g}, 1 \mathrm{mmol})$ and 2-hydroxy benzaldedye $2(2 \mathrm{mmol})$ had been refluxed in ethanol for $2 \mathrm{~h}$ [Hugo et al. 1987; Adem et al. 2012]. The obtained residue was filtered and purified with ethanol. The crude product was recrystallized from ethanol. Synthetic routes of compounds are given in scheme 1 .<smiles></smiles><smiles>O=Cc1ccccc1O</smiles><smiles>O=Cc1ccccc1O</smiles>

Scheme 1:Synthetic routes of compound 3.<smiles>Oc1ccccc1/C=N/c1cc2nc3ccccc3nc2cc1/N=C/c1ccccc1O</smiles>

yellow; Yield 86\%., M.P: $113-114^{\circ} \mathrm{C}$, MF: $\mathrm{C}_{26} \mathrm{H}_{18} \mathrm{~N}_{4} \mathrm{O}_{2}$; Elemental analysis: Calcd (\%):C,74.63;, $4.34 ; \mathrm{N}, 13.39$; found (\%):C,74.01;H,4.19; N,13.12; IR (KBr, cm $\left.{ }^{-1}\right): 3414$ (vO-H), 2923 (vAr-CH), $2853(v \mathrm{~N}=\mathrm{C}-\mathrm{H}), 1629(\mathrm{vC}=\mathrm{N}), 1597(\mathrm{vC}=\mathrm{C}), 1256$ (vC-N), 1223-831 (aromatic C-H in-plane bending vibration); ${ }^{1} \mathrm{H}$ NMR $\left(400 \mathrm{MHz}, \mathrm{DMSO}-d_{6}, \delta, \mathrm{ppm}\right): 13.53,12.92(\mathrm{O}-\mathrm{H})$; 8.256.27(m, Ar-H); 6.10( N=C-H -); ${ }^{13} \mathrm{C}$ NMR (100 MHz, DMSO- $d 6$, $\delta$, ppm): 159.84, $159.18(\mathrm{C}=\mathrm{N}), 106.36-142.22(\mathrm{Ar}-\mathrm{C})$.

\subsection{Computational details}

The synthesized compound 3 has been optimized using the DFT/ B3LYP method using 6-31G (d,p) method [Arockia doss et al. 2017]. The optimized structure was subjected to IR spectral analysis was carried out at the same level of theory. The calculated frequencies are scaled down by using single scaling factor 0.9608 [Arockia doss et al. 2015]. Mulliken, MEP and non-linear optical effects (NLO) were calculated from the optimized geometry of their molecules. The molecular orbital energies such as HOMO and LUMO for title compounds were calculated by using the above mentioned level theory. The above mentioned computation- al calculations were performed by using the Gaussian $03 \mathrm{~W}$ [Frisch et al. 2004] program package on a personal computer.

\section{Results and discussion}

The title compound is synthesised and confirmed by FT-IR, ${ }^{1} \mathrm{H}$ and ${ }^{13} \mathrm{C}$ NMR spectral methods. The identified compound is taken for further computational analysis.

\subsection{Conformational analysis}

The Schiff base analogue has rotatable bonds, and so several conformers (Fig.1) are possible for 3. These structures were subjected to AM1 computations method and the ground state energy, energy difference and dipole moment of conformers are presented in Table 1. From the calculated energies the conformer 1 is found to bemore stable. Therefore, we took conformer 1 for further studies.

Table 1: Calculated energies and energy differences of possible conformers of the 1

\begin{tabular}{|c|c|c|c|c|c|}
\hline \multirow{2}{*}{ Compound } & Energy & \multicolumn{3}{|c|}{ Energy difference } & \multirow[t]{2}{*}{ Dipole moment } \\
\hline & Hartee & Kcal & Hartee & Kcal & \\
\hline Conformer 1 & 0.17155 & 107.65232 & 0.00000 & 0.00000 & 2.28 \\
\hline Conformer 2 & 0.17693 & 111.02754 & -0.00538 & -3.37522 & 2.56 \\
\hline Conformer 3 & 0.18082 & 113.46491 & -0.00926 & -5.81259 & 1.64 \\
\hline Conformer 4 & 0.17168 & 107.72827 & -0.00012 & -0.07595 & 2.29 \\
\hline
\end{tabular}
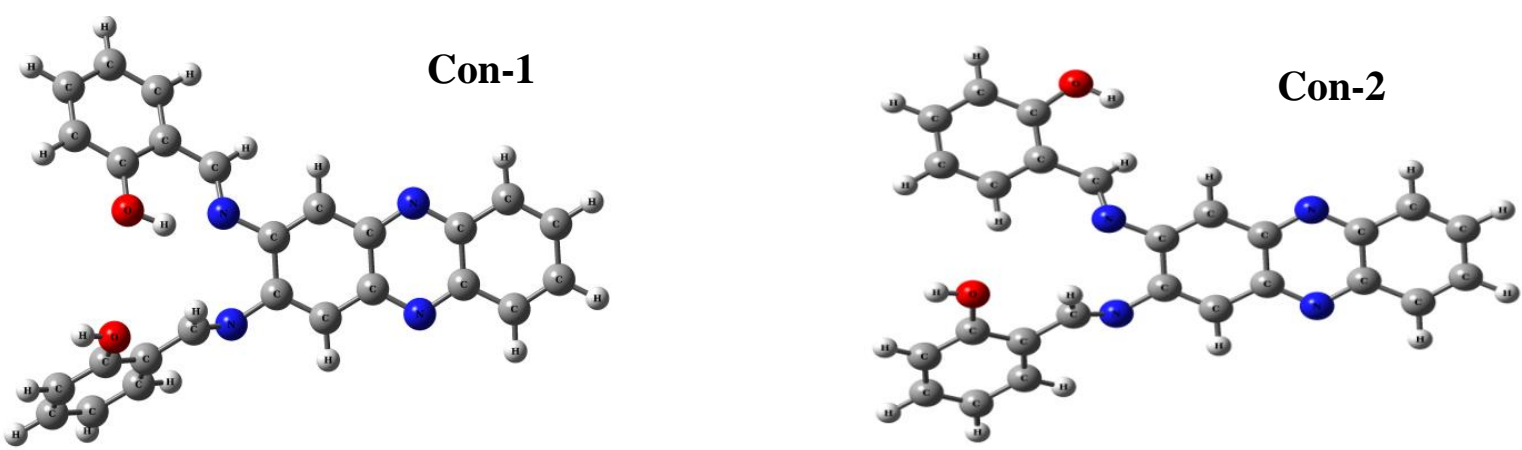

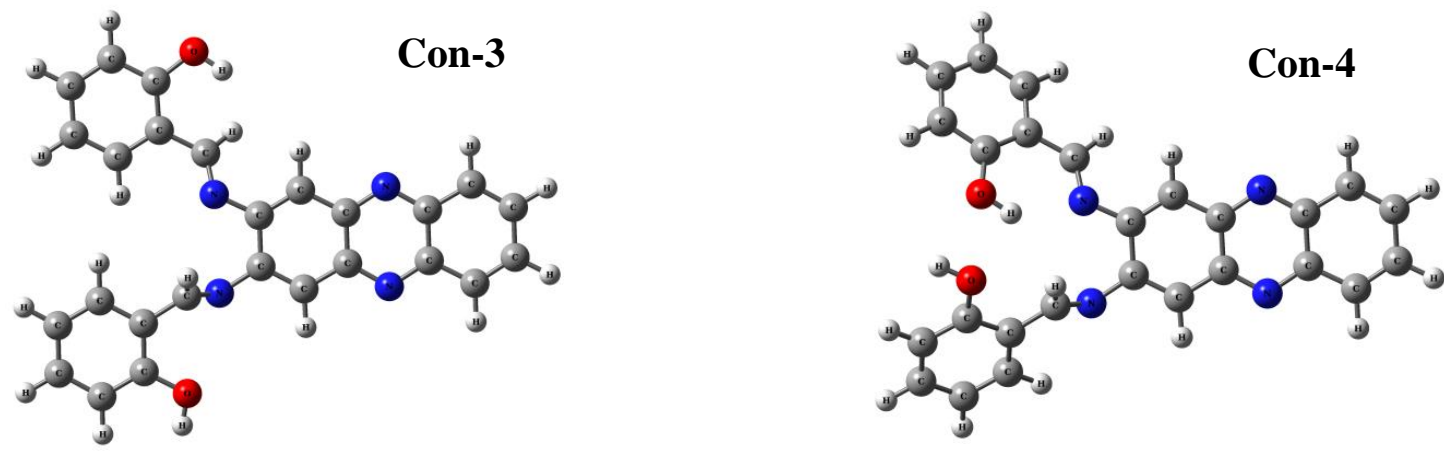

Fig. 1:Possible conformers of compound 3.

\subsection{Molecular geometry}

The optimized structural parameters such as bond lengths, bond and dihedral angles of 3 were determined at AM1 and DFTB3LYP/6-31G (d,p) level theories and are presented in Table 2 in accordance with the atom numbering scheme of the molecule shown in Fig. 2. The $\mathrm{C}-\mathrm{C}$ bond lengths of the benzene rings are $\sim 1.455$ (AM1) and $\sim 1.3751 \AA$ (B3LYP). The computed value by B3LYP/6-31G (d,p) shows excellent agreement with XRD value $1.388 \AA$

In Fig. 2, the intramolecular N.....H interactions of the azomethine nitrogen (N21) and hydroxyl group hydrogen (H50) in phenyl rings was indicated by decreasing bond length C26-O45
[1.3758(AM1) \& $1.3887 \AA$ (B3LYP)]and elongation of bond length O45-H46 [0.9692(AM1) \& $9.753 \AA$ (B3LYP)] and bond length between N21....H50 [1.1836(AM1) \& $1.7101 \AA$ (B3LYP]). This type interaction is absent in another azomethine nitrogen (N22), which is due to steric repulsion between hydroxyl group (see Fig. 1 Con-4).

From Table 2, it was revealed that steric repulsion between Phenazine atom and the phenyl ring lead to a non-planar molecular structure, which was evidence from the torsion angles-142.94 (AM1) and $-141.64^{\circ}$ (B3LYP) for C12-C11-N21-C24 \& 39.93 (AM1) and $39.79^{\circ}$ (B3LYP) for C9-C11-N21-C24 and $-60.05^{\circ}$ (AM1) and $-63.16^{\circ}$ (B3LYP) for C11-C12-N22-C23 \& $125.52^{\circ}$ (AM1) and $122.19^{\circ}$ (B3LYP) for C13-C12-N22-C23.

Table 2: Selected bond lengths, bond angles and dihedral angles of 3

\begin{tabular}{|c|c|c|c|c|c|}
\hline Bond length $(\AA)$ & AM1 & B3LYP & Bondangle $\left({ }^{\circ}\right)$ & AM1 & B3LYP \\
\hline $\mathrm{C} 1-\mathrm{C} 2$ & 1.3614 & 1.3751 & $\mathrm{C} 2-\mathrm{C} 1-\mathrm{C} 6$ & 121.09 & 120.70 \\
\hline $\mathrm{C} 2-\mathrm{C} 3$ & 1.4439 & 1.4268 & $\mathrm{C} 1-\mathrm{C} 2-\mathrm{C} 3$ & 120.41 & 120.10 \\
\hline $\mathrm{C} 3-\mathrm{C} 4$ & 1.4552 & 1.4459 & $\mathrm{C} 2-\mathrm{C} 3-\mathrm{C} 4$ & 118.50 & 119.24 \\
\hline C5-C6 & 1.3614 & 1.4271 & C2-C3-N20 & 120.26 & 119.24 \\
\hline C6-C1 & 1.4264 & 1.4302 & $\mathrm{C} 3-\mathrm{C} 4-\mathrm{C} 5$ & 118.47 & 119.07 \\
\hline C4-N19 & 1.3546 & 1.3571 & C3-C4-N19 & 121.30 & 121.33 \\
\hline $\mathrm{C} 3-\mathrm{N} 20$ & 1.3546 & 1.3575 & C3-N20-C8 & 117.38 & 117.43 \\
\hline C7-N19 & 1.3564 & 1.3547 & C4-N19-C7 & 117.44 & 117.52 \\
\hline $\mathrm{C} 8-\mathrm{N} 20$ & 1.3561 & 1.3527 & $\mathrm{C} 12-\mathrm{N} 22-\mathrm{C} 23$ & 121.23 & 123.43 \\
\hline C7-C13 & 1.4372 & 1.4214 & $\mathrm{C} 23-\mathrm{C} 25-\mathrm{C} 27$ & 123.18 & 121.71 \\
\hline $\mathrm{C} 8-\mathrm{C} 9$ & 1.4366 & 1.4226 & $\mathrm{C} 23-\mathrm{C} 25-\mathrm{C} 26$ & 118.19 & 119.81 \\
\hline C9-C11 & 1.3772 & 1.3809 & $\mathrm{C} 25-\mathrm{C} 26-\mathrm{O} 45$ & 116.82 & 116.99 \\
\hline $\mathrm{C} 11-\mathrm{C} 12$ & 1.4661 & 1.4581 & N22-C23-C25 & 122.63 & 121.84 \\
\hline C11-N21 & 1.4125 & 1.4134 & C24-C $35-C 37$ & 116.00 & 120.21 \\
\hline $\mathrm{C} 12-\mathrm{N} 22$ & 1.4131 & 1.4053 & $\mathrm{C} 24-\mathrm{C} 35-\mathrm{C} 36$ & 125.93 & 121.04 \\
\hline $\mathrm{N} 22-\mathrm{C} 23$ & 1.2906 & 1.2912 & $\mathrm{C} 35-\mathrm{C} 36-\mathrm{O} 47$ & 126.19 & 121.29 \\
\hline $\mathrm{C} 23-\mathrm{C} 25$ & 1.4682 & 1.4619 & H10-C9-C11-N21 & -2.35 & 1.86 \\
\hline $\mathrm{C} 25-\mathrm{C} 26$ & 1.4133 & 1.4110 & N21-C24-C35-C36 & 0.88 & 0.74 \\
\hline $\mathrm{C} 25-\mathrm{C} 27$ & 1.3979 & 1.4076 & N21-C24-C35-C37 & -179.39 & -179.28 \\
\hline $\mathrm{C} 26-\mathrm{O} 45$ & 1.3758 & 1.3887 & C12-C11-N21-C24 & -142.94 & -141.64 \\
\hline $\mathrm{O} 45-\mathrm{H} 46$ & 0.9692 & 0.9753 & C9-C11-N21-C24 & 39.93 & 39.79 \\
\hline C24-C35 & 1.4636 & 1.4452 & C24-C35-C36-O47 & -0.43 & -0.14 \\
\hline C35-C36 & 1.4078 & 1.4249 & C24-C35-C37-H40 & 0.52 & 0.10 \\
\hline $\mathrm{C} 36-\mathrm{O} 47$ & 1.3656 & 1.3632 & $\mathrm{H} 18-\mathrm{C} 13-\mathrm{C} 12-\mathrm{N} 22$ & -4.88 & -2.51 \\
\hline O47-H50 & 0.9726 & 1.0122 & $\mathrm{~N} 22-\mathrm{C} 23-\mathrm{C} 25-\mathrm{C} 26$ & -155.15 & -178.16 \\
\hline C35-C37 & 1.4116 & 1.4136 & $\mathrm{~N} 22-\mathrm{C} 23-\mathrm{C} 25-\mathrm{C} 27$ & 24.45 & 0.46 \\
\hline N21-H50 & 1.1836 & 1.7101 & C11-C12-N22-C23 & -60.05 & -63.16 \\
\hline \multirow[t]{3}{*}{ N22-H46 } & 4.8447 & 5.0201 & $\mathrm{C} 13-\mathrm{C} 12-\mathrm{N} 22-\mathrm{C} 23$ & 125.52 & 122.19 \\
\hline & & & $\mathrm{C} 23-\mathrm{C} 25-\mathrm{C} 26-\mathrm{O} 45$ & -2.30 & -2.54 \\
\hline & & & $\mathrm{C} 23-\mathrm{C} 25-\mathrm{C} 27-\mathrm{H} 30$ & 0.21 & 1.30 \\
\hline
\end{tabular}




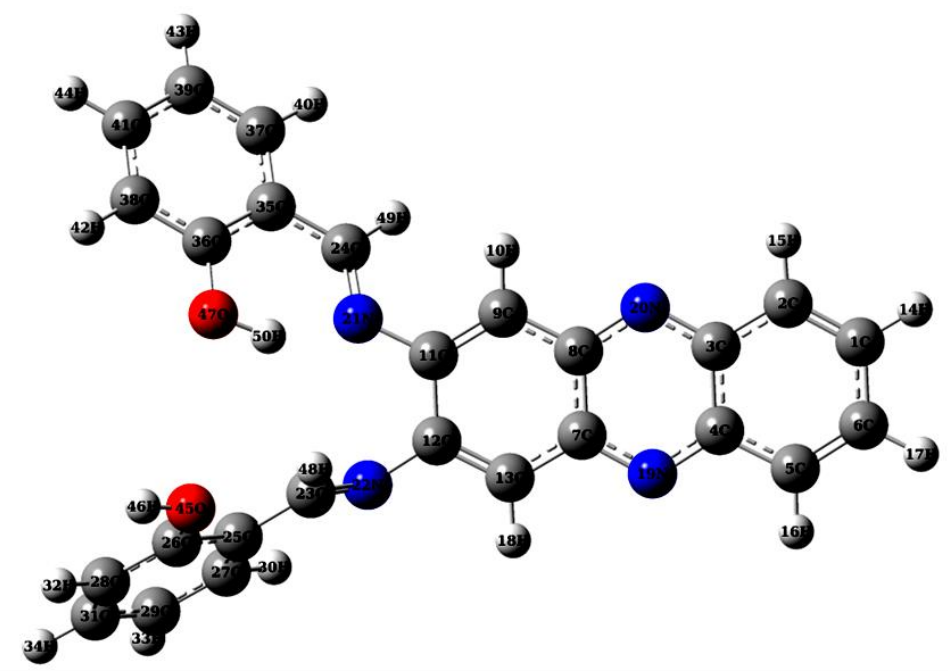

Fig. 2:Optimized structure and numbering pattern of 3 .

\subsection{Vibrational analysis}

The computational study was extended to IR spectroscopy for frequency analysis in order to support the assignment of experimental values of the vibration bands for 3 . The vibrational analysis was conducted by frequency calculations of the geometry optimized structure. No imaginary frequencies were found thus eliminating saddle points in the potential hyper energy surface.

Table 3:IR vibrational assignments of compound 3

\begin{tabular}{lllll}
\hline Assignments & Expt. & \multicolumn{3}{c}{ B3LYP } \\
\hline & & Unscaled & scaled & IR Intensity \\
vO-H & 3414 & 3682 & 3538 & 43.61 \\
vArC -H & 2923 & 3083 & 2962 & 14.6 \\
$\begin{array}{l}v C \text {-H } \\
\text { (azomethine) }\end{array}$ & 2853 & 2981 & 2864 & 52.0 .97 \\
& & & & \\
$v \mathrm{C}=\mathrm{N}$ & 1629 & 1702 & 1635 & 344.35 \\
$\mathrm{vC}=\mathrm{C}$ & 1597 & 1684 & 1618 & 63.85 \\
$\mathrm{vC}-\mathrm{N}$ & 1256 & 1324 & 1272 & 71.81 \\
& 1223 & 1289 & 1238 & 28.72 \\
Bring-H & 1131 & 1186 & 1140 & 253.67 \\
& 1021 & 1120 & 1076 & 83.66 \\
& 831 & 889 & 854 & 108.56 \\
\hline
\end{tabular}

The most characteristic band for out compounds is the $\mathrm{C}=\mathrm{N}$ imine bond stretch found at $1629 \mathrm{~cm}^{-1}$ which is in congruent with typical observed range of imine vibrations for related literature value. It

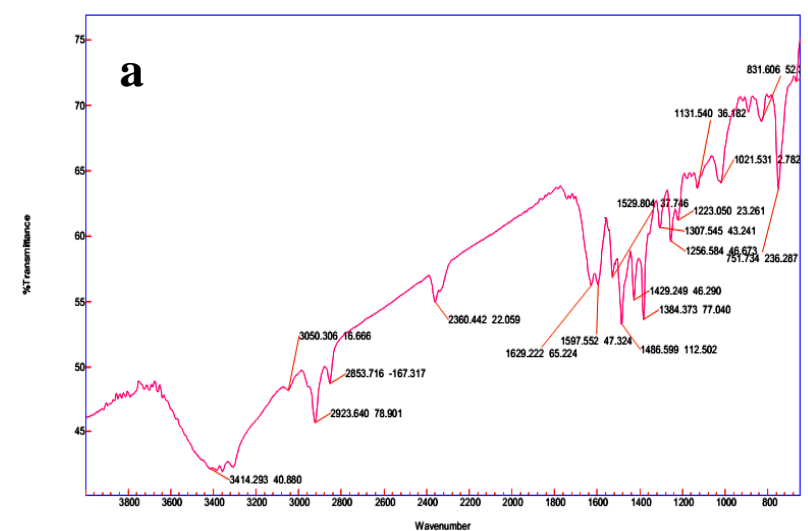

supports the formation of Schiff base. The calculated vibrational IR spectra showed a reliable agreement with experimental values although the frequencies slightly overestimated, mainly due to the omission of anharmonicity. The band at 3414 (Experimental) and 3538 (B3LYP) $\mathrm{cm}^{-1}$ is due to $\mathrm{O}-\mathrm{H} \mathrm{cm} \mathrm{cm}^{-1}$ stretching (Fig. 3). For aromatic compounds, the $\mathrm{C}-\mathrm{H}$ stretching mode [Silverstein et al. 2005 ] is usually observed in the region $2850-3000 \mathrm{~cm}^{-1}$. For title compounds, the $v \mathrm{ArC}-\mathrm{H}$ stretching modes are observed at $\sim 2923$ $\mathrm{cm}^{-1}$ in the IR spectrum. The scaled value $2962 \mathrm{~cm}^{-1}$ matches with experimental data.

Besides that, $(\mathrm{N}=\mathrm{C}-\mathrm{H})$ imino stretching band is observed around $2853 \mathrm{~cm}^{-1}$ (Table 4). The $\mathrm{C}=\mathrm{C}$ and $\mathrm{C}-\mathrm{N}$ stretching modes are normally expected in the spectral range $1680-800 \mathrm{~cm}^{-1}$ [Kitson et al. 1952]. For compound 3, it is interesting to mention that the most intense lines in the IR spectrum of appears at 1597 and1256 are attributed to $v \mathrm{C}=\mathrm{C}$ and $v \mathrm{C}-\mathrm{N}$ vibrational modes, respectively, corresponding computed scaled values are 1618, $1272 \mathrm{~cm}^{-1}$. Meanwhile the frequencies for $(\beta$ ring- $\mathrm{H})$ aromatic ring were recorded around $1223-831 \mathrm{~cm}^{-1}$ and its corresponding computed values are fall in the region $1238-854 \mathrm{~cm}^{-1}$. These values are in accordance with those reported in the literature [Savithiri et al. 2014; Savithiri et al. 2015; Evecen et al. 2016;Savithiri et al. 2016].

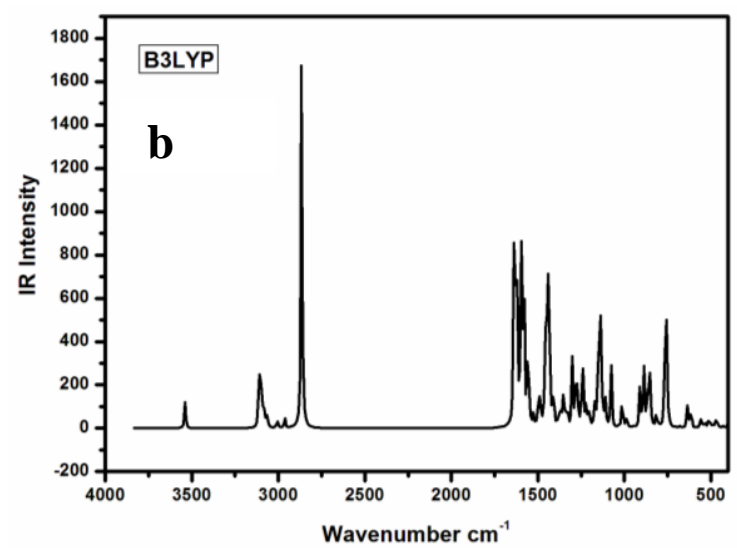

Figs. 3: (a) Experimental FT-IR Spectra (b) computed IR spectra of 3.

\subsection{Mulliken analysis}

The bonding capability of a molecule depends on the electronic charge on the atoms. The atomic charge values were obtained by the Mulliken and natural population analysis. Mulliken charge distributions were calculated by determining the electron population of each atom as defined by the $6-31 \mathrm{G}(\mathrm{d}, \mathrm{p})$ basis set. Therefore, we calculated Mulliken charge values by gas and different solvent phase, the values are tabulated in Table 4. 
Table 4: Mulliken charges of compound 3 in gas and solvent phase

\begin{tabular}{lllll}
\hline Atom & Gas & hexane & $\mathrm{CHCl}_{3}$ & Methanol \\
\hline C1 & -0.132 & -0.139 & -0.146 & -0.151 \\
C2 & -0.101 & -0.111 & -0.121 & -0.128 \\
C3 & 0.167 & 0.171 & 0.173 & 0.176 \\
C4 & 0.167 & 0.17 & 0.173 & 0.176 \\
C5 & -0.102 & -0.112 & -0.122 & -0.13 \\
C6 & -0.131 & -0.138 & -0.144 & -0.15 \\
C7 & -0.132 & 0.188 & 0.192 & 0.195 \\
C8 & 0.164 & 0.167 & 0.17 & 0.173 \\
C9 & -0.132 & -0.132 & -0.138 & -0.143 \\
C11 & 0.206 & 0.207 & 0.207 & 0.207 \\
C12 & 0.167 & 0.168 & 0.169 & 0.171 \\
N19 & -0.455 & -0.472 & -0.149 & -0.502 \\
N20 & -0.456 & -0.472 & -0.432 & -0.498 \\
N21 & -0.571 & -0.575 & -0.573 & -0.583 \\
N22 & -0.41 & -0.42 & -0.432 & -0.444 \\
C23 & 0.031 & 0.031 & 0.03 & 0.029 \\
H48 & 0.173 & 0.176 & 0.18 & 0.185 \\
C24 & 0.095 & 0.075 & 0.092 & 0.098 \\
H49 & 0.154 & 0.168 & 0.183 & 0.198 \\
C25 & 0.078 & 0.075 & 0.072 & 0.068 \\
C26 & 0.227 & 0.226 & 0.225 & 0.217 \\
O45 & -0.621 & -0.636 & -0.649 & -0.66 \\
H46 & 0.381 & 0.402 & 0.423 & 0.442 \\
C35 & 0.073 & 0.069 & 0.064 & 0.058 \\
C36 & 0.236 & 0.233 & 0.23 & 0.225 \\
O47 & -0.626 & -0.633 & -0.64 & -0.648 \\
H50 & 0.429 & 0.429 & 0.428 & 0.428 \\
\hline & & & &
\end{tabular}

Table 4 shows the effect upon the charge distribution induced by different states. The results indicated that the influences of different solvent were small but those arising from a change of state

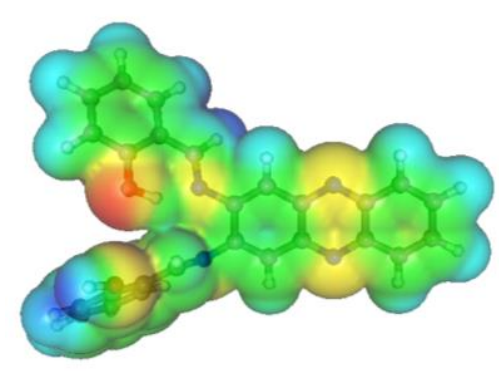

C

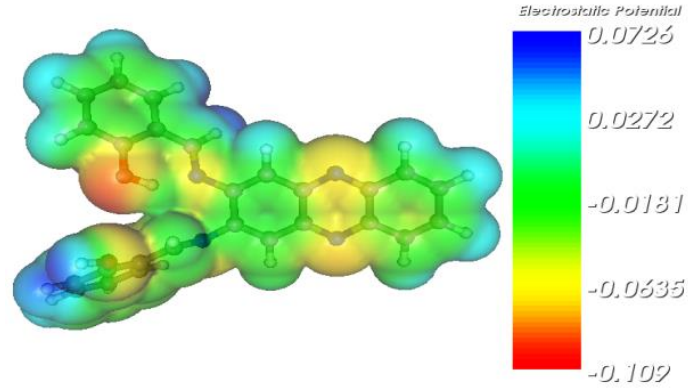

differed significantly. Actually, the charge distribution was nearly the same in water and a DMSO solution. For example, with reference to the $\mathrm{C} 24$ atoms, in the charge was $0.095,0.075,0.092$ in gas, hexane, chloroform respectively, while in methanol solution its charge changed to 0.098 . The results indicated that solvent polarity although the influence the charge distribution of atoms in title compound. It may indicate that methanol medium is suitable for the substitution reactions. Therefore methanol phase charges were considered for the discussion.

As we seen from Table 4, carbons atoms adjacent to electronegative atoms such nitrogen and oxygen atoms possesses positive charges remaining things have negative charges. It indicates that electronegative atoms drain electrons from carbon atoms that lead to positive values. Hydrogen atoms $\mathrm{H} 46$ and $\mathrm{H} 50$ both are attached to oxygen atoms, whereas H46 (0.442) high value than H50 (0.428). This may be reason of H50 atoms hydrogen bonding with $\mathrm{N} 21$ atom. This further confirms the anti orientation of $\mathrm{O}-\mathrm{H}$ group.

\subsection{Molecular electrostatic potential}

Molecular electrostatic potential of 3 was determined by B3LYP/6-31G (d,p) in gas and solvent phases. It provides a visual method to understand the relative polarity of the molecule. An electron density isosurface mapped with electrostatic potential surface depicts the size, shape, charge density and site of chemical reactivity of the molecule. The different values of the electrostatic potential at the surface are represented by different colors.

$\mathrm{b}$

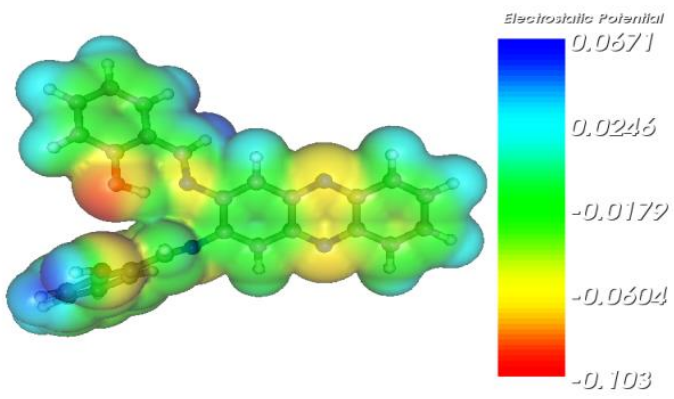

d

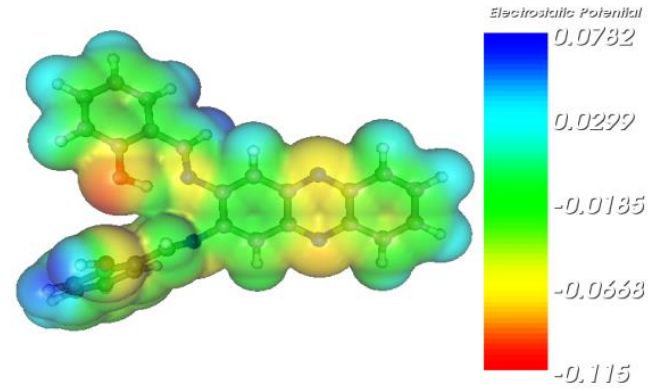

Figs. 4:MEP map of Compound 3 in (a) Gas, (b) Hexane, (c) Chloroform and (d) Methanol phase, respectively.

The negative (red and yellow) regions of MEP are associated with electrophilic reactivity and positive (blue) regions to nucleophilic reactivity. The $\mathrm{C}=\mathrm{N}$, $\mathrm{O}-\mathrm{H}$ groups are suitable sites for electrophilic reaction. The blue in Figs. 4 shows the strongest attraction and red indicates the strongest repulsion in the title molecule, which is also supported by Mulliken charge analysis.

\subsection{Electronic spectral analysis}

The electronic spectra of the title compound in hexane, chloroform and methanol solvents were recorded and shown in Fig. 5. There is no absorption band around 400 and $1000 \mathrm{~nm}$. The absence of absorption in the visible region in the Schiff base makes them suitable candidate for NLO property. [Savithiri et al. 2016]. 

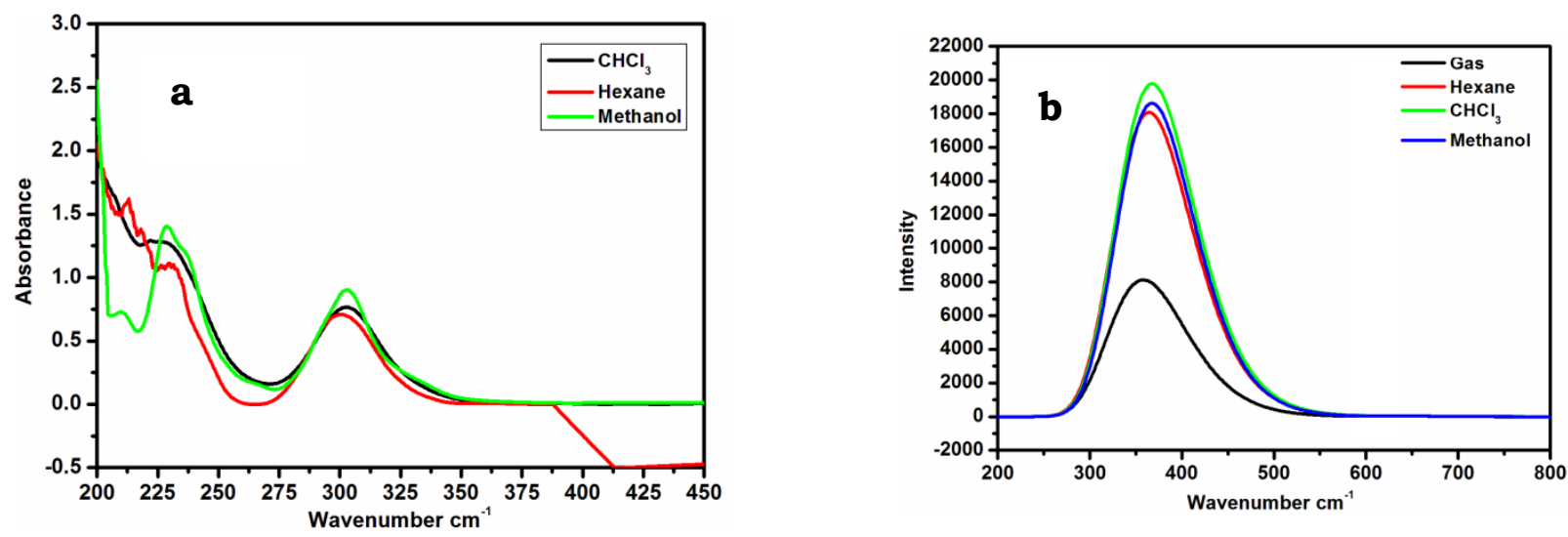

Figs. 5: (a) Experimental (b) computed UV-vis spectrum of 3.

As seen from Fig. 5a, electronic absorption spectra showed two bands at 299 and $230 \mathrm{~nm}$ for hexane at 300 and $277 \mathrm{~nm}$ for chloroform at 303 and $228 \mathrm{~nm}$ for methanol. Electronic absorption spectra were calculated using the TD-DFT method based on the B3LYP/6-31G $(\mathrm{d}, \mathrm{p})$ level optimized structure in gas phase. The calculated results are listed in Table 5 along with the experimental absorption spectral data. For TD-DFTcalculations, the theoretical absorption bands are predicted at $345.90,329$ and $257.03 \mathrm{~nm}$ in gas phase, at $348.86,321.37$ and $245.07 \mathrm{~nm}$ in hexane at 348.07 , 319.03 and $263.90 \mathrm{~nm}$ in chloroform and $345.42,320.70$ and $258.12 \mathrm{~nm}$ in methanol. The bands around $300 \mathrm{~nm}$ are assigned to $\mathrm{n}-\pi^{*}$ transition. The bands around $230 \mathrm{~nm}$ are assigned to $\pi-\pi^{*}$ transition. The solvent in which the absorbing species is dissolved also has an effect on the spectrum of the species. Peaks resulting from $\mathrm{n}-\pi^{*}$ transitions are shifted to shorter wavelengths (blue shift) with increasing solvent polarity. This emerges from increased solvation of the lone pair, which brings down the energy of the $\mathrm{n}$ orbital. Normally (but not always), the reverse (i.e. red shift) is seen for $\pi-\pi^{*}$ transitions. This is brought about by attractive polarisation forces between the solvent and absorber, which decrease the energy levels of both the excitedand unexcited states. This effect is greater for the excited state, and so the energy difference between the excited and unexcitedstates are slightly reduced resulting in a small red shift. This effect also influences $\mathrm{n}-\pi$ *transitions but is overshadowed by the blue shift resulting from solvation of lone pairs. The main contributions of the transitions were designated with the help of SWizard program [Gorelsky et al. 2010]. In methanol phase, the maximum absorption wavelength corresponds to the electronic transition from the HOMO-LUMO with $96 \%$ contribution, the transition on HOMOLUMO + 1 with $95 \%$ and the transition HOMO-2-LUMO+2 with $46 \%$.

Table 5: Computed and experimental absorption maxima $\left(\Lambda_{\max }, \mathrm{Nm}\right)$, oscillator strength $(f)$ and electronic excitation energies $(\mathrm{E}$, eV) of 3

\begin{tabular}{|c|c|c|c|c|c|}
\hline State & Cal. $\lambda_{\max }(\mathrm{nm})$ & Expt. $\lambda_{\max }(\mathrm{nm})$ & $\begin{array}{l}\text { Osicillator } \\
\text { Strength }(f)\end{array}$ & $\mathrm{E}(\mathrm{eV})$ & $\begin{array}{l}\text { Main contributing configura- } \\
\text { tions }\end{array}$ \\
\hline \multirow{4}{*}{ Gas phase } & 345.90 & & 0.0551 & 3.58 & $\begin{array}{l}\mathrm{H} \rightarrow \mathrm{L}(89 \%) \\
\mathrm{H}-1 \rightarrow \mathrm{L}(10 \%) \\
\mathrm{H} \rightarrow \mathrm{L}+1(84 \%)\end{array}$ \\
\hline & 329 & & 0.0024 & 3.77 & $\mathrm{H}-2 \rightarrow \mathrm{L}(10 \%)$ \\
\hline & & & & & $\begin{array}{l}\mathrm{H}-2 \rightarrow \mathrm{L}+2(46 \%) \\
\mathrm{H}-4 \rightarrow \mathrm{L}(11 \%)\end{array}$ \\
\hline & 257.03 & & 0.1595 & 4.82 & $\begin{array}{l}\mathrm{H}-5 \rightarrow \mathrm{L}+2(10 \%) \\
\mathrm{H} \rightarrow \mathrm{L}+2(6 \%)\end{array}$ \\
\hline \multirow{3}{*}{ Hexane } & 348.86 & & 0.1036 & 3.55 & $\mathrm{H} \rightarrow \mathrm{L}(91 \%)$ \\
\hline & 321.37 & 299 & 0.0047 & 3.86 & $\begin{array}{l}\mathrm{H} \rightarrow \mathrm{L}+1(93 \%) \\
\mathrm{H}-2 \rightarrow \mathrm{L}(07 \%)\end{array}$ \\
\hline & 245.07 & 230 & 0.3616 & 5.06 & $\begin{array}{l}\mathrm{H}-2 \rightarrow \mathrm{L}+2(45 \%) \\
\mathrm{H}-4 \rightarrow \mathrm{L}(12 \%) \\
\mathrm{H}-5 \rightarrow \mathrm{L}+2(13 \%)\end{array}$ \\
\hline \multirow{4}{*}{ Chloroform } & 348.07 & & 0.1074 & 3.56 & $\begin{array}{l}\mathrm{H} \rightarrow \mathrm{L}(90 \%) \\
\mathrm{H}-1 \rightarrow \mathrm{L}(05 \%) \\
\mathrm{H} \rightarrow \mathrm{L}+1(73 \%)\end{array}$ \\
\hline & 319.03 & 300 & 0.3818 & 3.89 & $\mathrm{H}-2 \rightarrow \mathrm{L}(21 \%)$ \\
\hline & 263.90 & 227 & 0.0174 & 4.70 & $\begin{array}{l}\mathrm{H}-6 \rightarrow \mathrm{L}(62 \%) \\
\mathrm{H}-4 \rightarrow \mathrm{L}(11 \%) \\
\mathrm{H}-3 \rightarrow \mathrm{L}(10 \%)\end{array}$ \\
\hline & 345.42 & & 0.0856 & 3.59 & $\mathrm{H} \rightarrow \mathrm{L}(96 \%)$ \\
\hline \multirow{2}{*}{ Methanol } & 320.70 & 303 & 0.3786 & 3.87 & $\begin{array}{l}\mathrm{H} \rightarrow \mathrm{L}+1(95 \%) \\
\mathrm{H}-2 \rightarrow \mathrm{L}(04 \%)\end{array}$ \\
\hline & 258.12 & 228 & 0.0073 & 4.80 & $\begin{array}{l}\mathrm{H}-2 \rightarrow \mathrm{L}+2(46 \%) \\
\mathrm{H}-4 \rightarrow \mathrm{L}(10 \%) \\
\mathrm{H}-5 \rightarrow \mathrm{L}+2(13 \%)\end{array}$ \\
\hline
\end{tabular}




\subsection{Analysis of frontier molecular orbitals}

HOMO-LUMO energies were calculated using DFT-B3LYP/6-31G $(\mathrm{d}, \mathrm{p})$ level theory and the values of compound 3 are given in Table 6 . Conjugated molecules are characterized by small gaps between the highest occupied molecular orbital and lowest unoccupied molecular orbital.

Table 7: Calculated energy values $(\mathrm{eV})$ of 3 in Gas and Methanol Phase

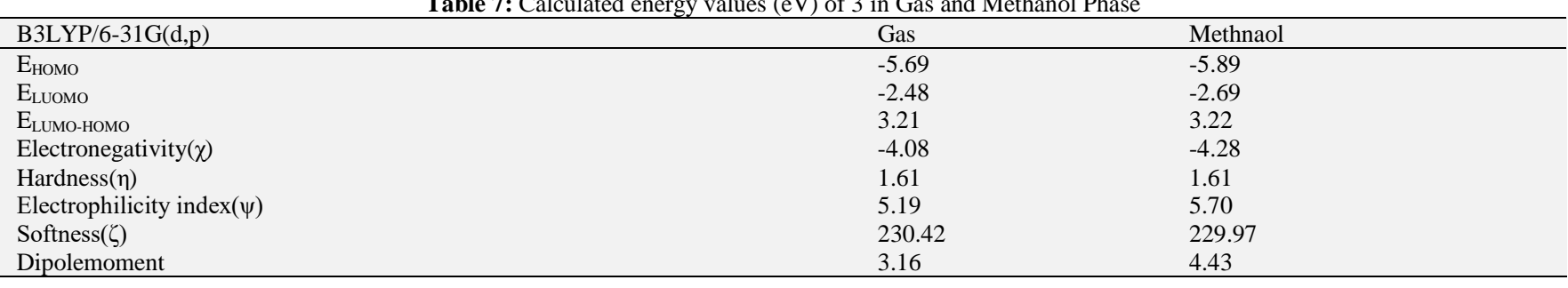
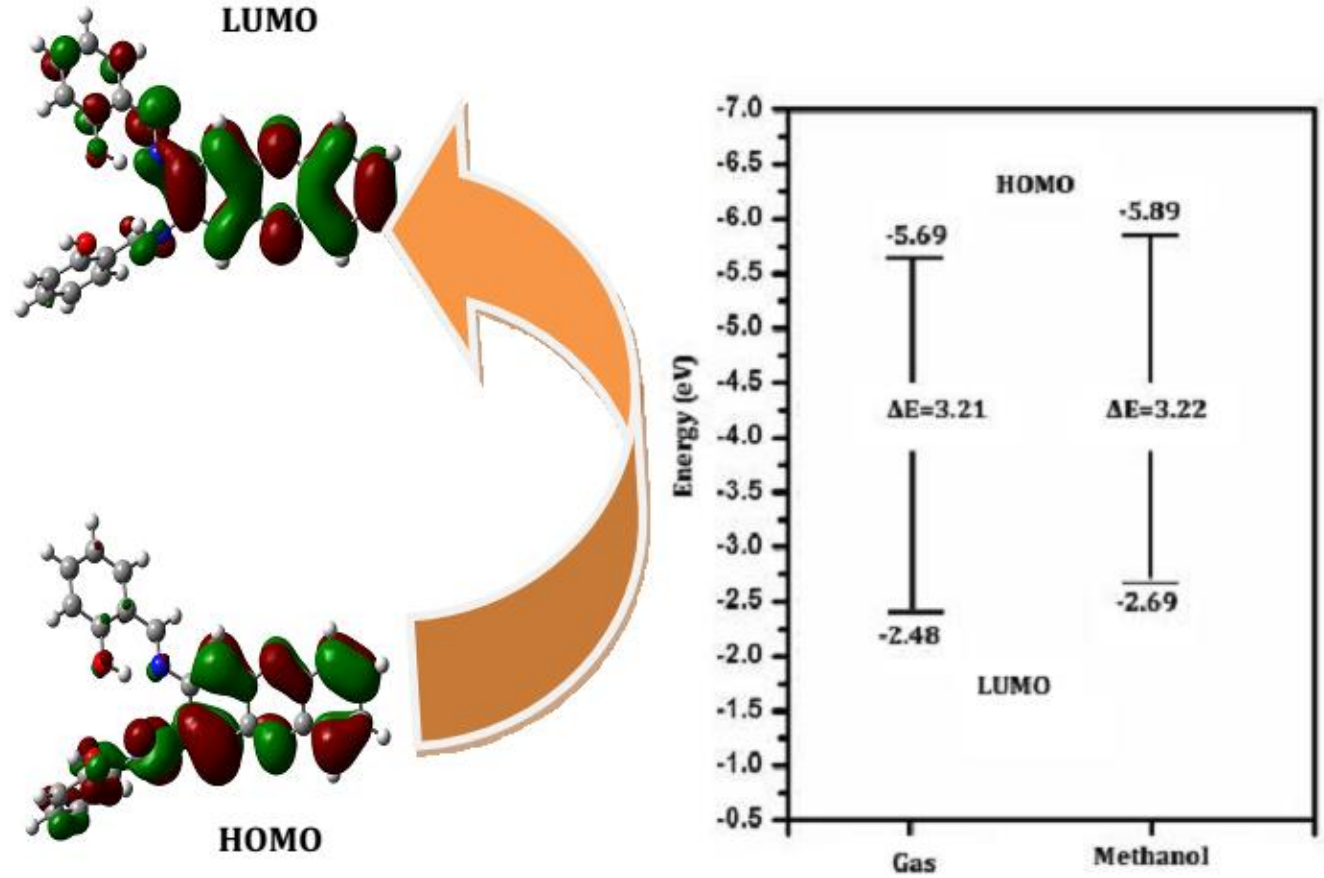

Fig. 6: The frontier molecular orbitals of compound 3.

The electronic absorption corresponds to the transition from the ground state to the first excited state and is one electron excitation from the highest occupied molecular orbital to the lowest unoccupied molecular orbital. While the energy of HOMO is directly related to ionization potential and LUMO energy is to electron affinity. Recently, the energy gap between HOMO and LUMO has been used to confirm the bioactivity from ICT [Omri et al. 2016; Kosar et al. 2011]. The atomic orbital compositions of the frontier molecular orbitals are shown in Fig. 6.

It is clear from the figure that, the HOMO lying at -5.69 and -5.89 $\mathrm{eV}$ in gas and methanol phase respectively, while LUMO lying at -2.48 and $-2.69 \mathrm{eV}$ in gas and methanol phase, respectively. The value of energy gap between the HOMO-LUMO is -3.21 and $-3.20 \mathrm{eV}$ in gas and methanol phase, respectively. The energy gap of HOMO- LUMO explains the eventual charge transfer interactions that take place within the molecule. Furthermore, in going from solvent phase to gas phase, the decreasing value of the energy gap makes the molecule more stable. The dipole moment is another important electronic property in a molecule. For example higher the dipole moment, the stronger will be the intermolecular interactions. The calculated dipole moment values are given in Table 7. Based on predicted dipole moment values, it is found that, in going to the solvent phase from (4.43D in methanol) from gas phase $(3.16 \mathrm{D})$, the dipole moment value decreases (Table 7) which indicates that polarity of solvent influences the dipole moment of the studied molecule. The values of electronegativity, chemical hardness, softness and electrophilicity index are also given in Table 7.

\subsection{Non-linear optical (NLO) analysis}

NLO is at the forefront of current research because it provides the key functions of frequency shifting, optical modulation, optical switching, optical logic and optical memory for the emerging areas such as telecommunications, signal processing and optical interconnections [Bharathi et al. 2017; Srinivasan et al. 2015]. In discussing nonlinear optical properties, the polarization of the molecule by an external radiation field is often approximated as the creation of an induced dipole moment by an external electric field. The hyperpolarizability $\left(\beta_{0}\right)$ of a molecular system is calculated using B3LYP/6-31G $(\mathrm{d}, \mathrm{p})$ method, based on the finite field approach. The dipole moment $(\mu)$, polarisabilty $(\alpha)$ and the total hyperpolarizabilty $\left(\beta_{0}\right)$ are related directly to the nonlinear optical efficiency of the molecule.

The calculated hyperpolarizability $\left(\beta_{0}\right)$ and dipolemoment $(\mu)$ of the compound are $1.30 \times 10^{-30} \mathrm{esu}$ and $3.1696 \mathrm{D}$, respectively [Table 8]. As we compare the hyperpolarizability $\left(\beta_{0}\right)$ of 3 with urea [Zong-ming Jin et al. 1998], the value is 3.5 times greater than that of urea. High $\beta_{0}$ value is a required property of a NLO material. It is possible to sustain nonlinearity at the macro level by crystal designing using proper substituents. The high value of hyperpolarizability of 3 is due to the donor characteristic of nitrogen and oxygen atoms. Therefore, the title compound has a potential use in the development of non-linear optical materials. 
Table 8: Dipole moment, polarisabiltiy, hperpolarisabiltyof 3 calculated using B3LYP method using 6-31G (d,p) basis Set.

\begin{tabular}{llll}
\hline & Dipolemoment (D) & Parameter & $\begin{array}{l}\text { Hyperpolarisability } \\
\text { (a.u) }\end{array}$ \\
\hline$\mu_{\mathrm{x}}$ & -2.9647 & $\beta_{\mathrm{xxx}}$ & -0.9185 \\
$\mu_{\mathrm{y}}$ & 1.0921 & $\beta_{\mathrm{yyy}}$ & 53.9026 \\
$\mu_{\mathrm{z}}$ & 0.2527 & $\beta_{\mathrm{zzz}}$ & 21.831 \\
$\mu_{\mathrm{total}}$ & 3.1696 & $\beta_{\mathrm{xyy}}$ & -90.043 \\
Parameter & Polarisability (a.u) & $\beta_{\mathrm{xxy}}$ & -50.241 \\
$\alpha_{\mathrm{xx}}$ & 141.97 & $\beta_{\mathrm{xxz}}$ & 60.8824 \\
$\alpha_{\mathrm{yy}}$ & 167.42 & $\beta_{\mathrm{xzz}}$ & -52.387 \\
$\alpha_{\mathrm{zz}}$ & 180.28 & $\beta_{\mathrm{yzz}}$ & -20.652 \\
$\alpha_{\mathrm{xy}}$ & 7.34 & $\beta_{\mathrm{yyz}}$ & -25.269 \\
$\alpha_{\mathrm{xz}}$ & -4.82 & $\beta_{\mathrm{xyz}}$ & 13.9959 \\
$\alpha_{\mathrm{yz}}$ & -5.28 & $\beta_{0}(\mathrm{esu})$ & $1.30 \mathrm{x} 10^{-30}$ \\
$\alpha_{\mathrm{o}}(\mathrm{esu})$ & $2.40 \times 10^{-23}$ & & \\
$\Delta \alpha(\mathrm{esu})$ & $6.40 \times 10^{-24}$ & & \\
\hline
\end{tabular}

\subsection{Thermodynamic properties}

The values of some thermodynamic parameters such as zeropoint vibrational energy (ZPVE), thermal energy, specific heat capacity, rotational constants, entropy and dipole moment of 3 were calculated by DFT/B3LYP method at $298.15 \mathrm{~K}$ and $1.00 \mathrm{~atm}$ pressure and listed in Table 9.

Table 9: Calculated thermo dynamical parameters of 3

\begin{tabular}{ll}
\hline Parameter & B3LYP/6-31G(d,p) \\
\hline SCF energy (a.u) & -1370.68157520 \\
Zero point energy $\left(\mathrm{kcal} \mathrm{mol}^{-1}\right)$ & 242.62154 \\
Rotational constants $(\mathrm{GHz})$ & \\
$\mathrm{A}$ & 0.18838 \\
$\mathrm{~B}$ & 0.07105 \\
$\mathrm{C}$ & 0.05417 \\
Entropy (S) (cal mol & $\left.\mathrm{K}^{-1}\right)$ \\
Translational & 173.201 \\
Rotational & 43.983 \\
Vibrational & 37.337 \\
Dipole Moment (Debye) & 91.882 \\
\hline
\end{tabular}

The global minimum energy obtained for structure optimization of 91 is -1370.68157520 a.u for B3LYP with 6-31G (d,p) basis set. The zeropoint vibrational energy obtained is 242.62154 . The thermal energy is also in the same trend as the global minimum energy. Dipole moment reflects the molecular charge distribution and is given as a vector in three dimensions. Therefore, it can be used as descriptor to depict the charge movement across the mole- cule. Direction of the dipole moment vector in a molecule depends on the centres of positive and negative charges. The standard statistical thermodynamic functions such as heat capacity (C), entropy $(\mathrm{S})$ and enthalpy changes $(\Delta \mathrm{H})$ heat capacity $\left(\mathrm{C}_{\mathrm{p}, \mathrm{m}}^{0}\right)$, entropy $\left(\mathrm{S}_{\mathrm{m}}^{0}\right)$, and enthalpy changes $\left(\mathrm{H}^{0} \mathrm{~m}\right)$ for the title compound were obtained on the basis of vibrational analysis, using DFTB3LYP/6-31G(d.p) method and listed in Table 10.

Table 10: Thermodynamic properties at different temperatures at the B3LYP/6-31G (d,p) Level for 3 .

\begin{tabular}{llll}
\hline $\mathrm{T}(\mathrm{K})$ & $\mathrm{C}_{\mathrm{p} . \mathrm{m}}^{0}\left(\mathrm{cal} \mathrm{mol}^{-1} \mathrm{~K}^{-1}\right)$ & $\mathrm{S}_{\mathrm{m}}^{0}\left(\mathrm{cal} \mathrm{mol}^{-1} \mathrm{~K}^{-1}\right)$ & $\Delta \mathrm{H}_{\mathrm{m}}^{0}\left(\mathrm{kcal} \mathrm{mol}^{-1}\right)$ \\
\hline 100 & 159.65 & 438.56 & 10.16 \\
200 & 284.3 & 586.19 & 32.17 \\
298.15 & 419.18 & 724.78 & 66.68 \\
300 & 421.7 & 727.38 & 67.46 \\
400 & 550.64 & 866.76 & 116.22 \\
500 & 659.18 & 1001.71 & 176.89 \\
600 & 746.43 & 1129.9 & 247.34 \\
700 & 816.16 & 1250.4 & 325.6 \\
800 & 872.48 & 1363.19 & 410.12 \\
900 & 918.63 & 1468.7 & 499.75 \\
1000 & 956.95 & 1567.53 & 593.59 \\
\hline
\end{tabular}

From Table 10, it can be observed that these thermodynamic functions increase with temperature ranging from 100 to $1000 \mathrm{~K}$ due to the fact that the molecular vibrational intensities increase with temperature [Wei et al. 2009]. The correlation equations between heat capacity, entropy, enthalpy changes and temperatures are fitted by quadratic formulas. The corresponding fitting factors $\left(\mathrm{R}^{2}\right)$ for these thermodynamic properties are $0.99938,0.99999$ and 1 , respectively. The corresponding fitting equations are as follows and the correlation graphics of those shown in Fig. 9.

$$
\begin{aligned}
& \mathrm{C}_{\mathrm{p} . \mathrm{m}}^{0}=3.14198+1.59959 \mathrm{~T}-5.2589 \times 10-4 \mathrm{~T}^{2}\left(\mathrm{R}^{2}=0.99938, \mathrm{SD}\right. \\
& =8.07468)
\end{aligned}
$$

$\mathrm{S}^{0} \mathrm{~m}=289.04823+1.50602 \mathrm{~T}-1.0108 \mathrm{X} 10-4 \mathrm{~T}^{2}\left(\mathrm{R}^{2}=0.99999, \mathrm{SD}\right.$ $=0$ 1.03545)

\section{$\mathrm{H}^{0} \mathrm{~m}=5.17843-0.035 \mathrm{~T}+8.90537 \mathrm{X} 10-4 \mathrm{~T}^{2}\left(\mathrm{R}^{2}=1, \mathrm{SD}=\right.$} 0.33834 )

It is to be mentioned that all the thermodynamic calculations were done for gas phase and they could not be used for solution.

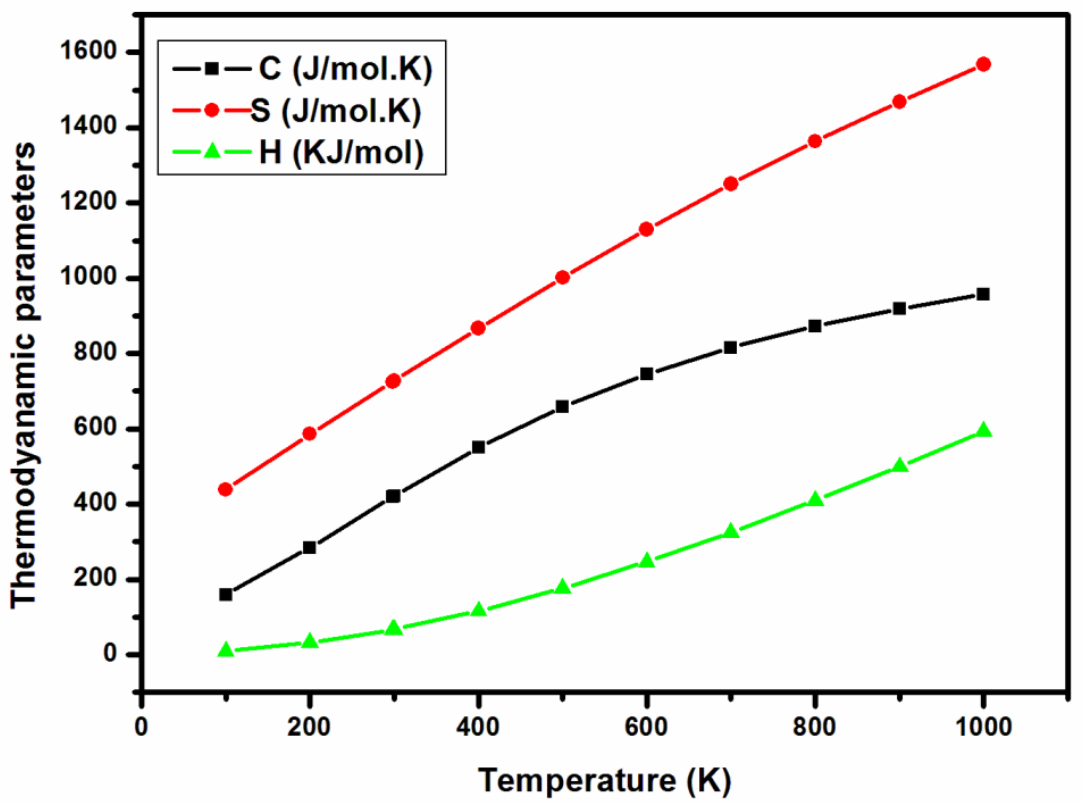

Fig. 9: Thermodynamic properties at different temperatures. 


\section{Conclusion}

In the present study, we have synthesized 2, 2'-((1E, 1'E)phenazine-2,3dilbis(azanylylidene))bis(methanylylidene))diphenol compound and characterized by IR UV-vis, IR, ${ }^{1} \mathrm{H}$ NMR and ${ }^{13} \mathrm{C}$ NMR spectral techniques. The computational results diagnose the most stable conformer of compound 3. In order to obtain the information about the influence of intramolecular interaction on the molecule the calculated geometries of title molecule was compared with experimental data. The overlapping of atomic orbitals along with their predicted energy is explained on the basis of HOMO-LUMO energy gap calculations. The electric dipole moments and hyperpolarizability of the compound studied have been calculated by DFT method. This result shows the NLO behaviour of title compound. The Mulliken, MEP surface and thermodynamic parameters are also predicted.

\section{References}

[1] Amr, A. E., Sabry, N. M., Abdalla, M. M. \& Abdel Wahab, B. F (2008). Synthesis, antiarrhythmic and anticoagulant activities of novel thiazolo derivatives from methyl 2-(thiazol-2- ylcarbamoyl) acetate. Eur. J. Med. Chem., 44, 725-735 https://doi.org/10.1016/j.ejmech.2008.05.004.

[2] Said, A. S., Amr, A. E., Sabry, N.M.\& M.M. Abdalla. (2009). Analgesic, anticonvulsant and anti-inflammatory activities of some synthesized benzodiazipine, triazolopyrimidine and bisimide derivatives. Eur. J. Med. Chem., 44, 4787-4792. https://doi.org/10.1016/j.ejmech.2009.07.013.

[3] Mohamed, S. F., Flefel, E. M., Amr, A.E.\& Abd El Shafy, D. N. (2010).Anti-HSV-1 activity and mechanism of action of some new synthesized substituted pyrimidine, thiopyrimidine and thiazolopyrimidine derivatives. Eur. J. Med. Chem., 45, 1494-1501. https://doi.org/10.1016/j.ejmech.2009.12.057.

[4] Al-Omar, M. A., \& Amr, A. E. (2010). Synthesis of some new pyridine-2, 6-carboxamide-derived Schiff bases as potential antimicrobial agents. Molecules, 15, 4711-4721. https://doi.org/10.3390/molecules15074711.

[5] Al-Salahi, R. A., Al-Omar, M. A., \& Amr, A. E. (2010). Synthesis of chiral macrocyclic or linear pyridine carboxamides from pyridine-2, 6-dicarbonyl dichloride as antimicrobial agents. Molecules, 15, 6588-6597. https://doi.org/10.3390/molecules15096588

[6] Moustafa, A.H., Assy, M.G., Amr, A. E., \& Saber, R.M (2011).Studies on the chemical reactivity of Ethyl 4-sulfanyl-6methyl-2- phenylpyrimidine-5-carboxylate. Curr. Org. Chem., 15, 1661-1668. https://doi.org/10.2174/138527211795378119.

[7] Ghozlan, S. A.S., Al-Omar, M. A., Amr, A. E., Khalil, K. \& Abd El-Wahab, A. A. (2011). Synthesis and antimicrobial activity of some heterocyclic 2, 6-bis (substituted)-1, 3, 4-thiadiazolo-, oxadiazolo-, andoxathiazolidino-pyridinederivativesfrom2, 6-pyridine dicarboxylic acid dihydrazide. J. Heterocycl. Chem., 48, $1103-$ 1110. https://doi.org/10.1002/jhet.690.

[8] Al-Omar, M.A., Amr, A.E., \& Al-Salahi, R.A. (2010). Antiinflammatory, analgesic, anticonvulsant and antiparkinsonian activities of some pyridine derivatives using 2, 6-disubstituted isonicotinic acid hydrazides. Archiv der Phaemazie, 343, 648-656. https://doi.org/10.1002/ardp.201000088.

[9] Sayed, H.H., Abbas, H.S., Morsi, E.M.H., Amr, A. E., \& Abdelwahad, N.A.M. (2010). Antimicrobial activity of some synthesized glucopyranosyl-pyrimidine carbonitrile and fused pyrimidine systems. ActaPharmaceutica, 60, 479-491. https://doi.org/10.2478/v10007-010-0033-8.

[10] Abdel-Hafez, N.A., Mohamed, A.M., Amr, A.E., \& Abdalla, M. M (2009).Antiarrhythmic activities of some newly synthesized tricyclic and tetracyclic thienopyridine derivatives. ScientiaPharmaceutica, 77, 539-553. https://doi.org/10.3797/scipharm.0905-06.

[11] Yousif, E., Salih, N., \& Salimon. J. (2011). Improvement of the photostabilization of PVC films in the presence of $2 \mathrm{~N}$-salicylidene5-(substituted)-1,3,4- thiadiazole. J. Appl. Polym. Sci., 120, $2207-$ 2214.https://doi.org/10.1002/app.33463.

[12] Li, Y., Yang, Z.S., Zhang, H., Cao, B.J., \& Wang, F.D. (2003). Artemisinin derivatives bearing Mannich base group: synthesis and antimalarial activity. Bioorg. Med. Chem., 11, 4363-4368.

[13] Hanan F. Abd El-Halima Gehad, G., Mohamed Eman, A.M \&Khalilc. (2017). Synthesis, spectral, thermal and biological stud- ies of mixed ligand complexes with newly prepared Schiff base and 1,10-phenanthroline ligands, J. Mol. Struct., 1146, 153-163. https://doi.org/10.1016/j.molstruc.2017.05.092.

[14] NevinS üle manoğlu, Reşat Ustabas, Sahin Direkel Yelda Bingöl Alpaslan., \& Yasemin Ünvere. (2017). 1, 2, 4-triazole derivative with Schiff base; thiol-thionetautomerism, DFT study and antileishmanial activity. $\begin{array}{llll}\text { J. Mol. } & \text { Struct., } & \text { 82-87. }\end{array}$ https://doi.org/10.1016/j.molstruc.2017.08.075.

[15] Nasser MohammedHosny., Hussien, M. A., Fatima M. R., \& NagwaNawar. (2017). Synthesis, spectral, thermal and optical properties of Schiff-base complexes derived from 2(E)-2-((z)-4-hydroxypent-3-en-2-ylideneamino)-5guanidinopentanoic acid and acetylacetone. J. Mol. Struct., 1143, 176-183. https://doi.org/10.1016/j.molstruc.2017.04.063.

[16] Adem, C., Demet, G., Aydin, T., \&Seher, B. (2012). Spectral Characterization and Antimicrobial Activity of Some Schiff Bases Derived from 4-Chloro-2-aminophenol and Various Salicylaldehyde

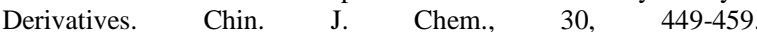
https://doi.org/10.1002/cjoc.201180473.

[17] Hugo, W.B., Russell, P.D. (1987). Pharmaceutical Microbiology, Blackwell Scientific Publication: Oxford.

[18] Arockia doss, M., Rajarajan, G., Thanikachalam, V., Selvanayagam, S., \& Sridhar, B. (2017). Synthesis, spectroscopic (UVVis, FT-IR and NMR), single crystal XRD of 3, 5-diethyl-2, 6-di (thiophen-2-yl) piperidin-4-on-1-ium picrate: A comprehensive experimental and computational study. J. Mol. Struct., 1128: 268-278. https://doi.org/10.1016/j.molstruc.2016.08.065.

[19] Arockia doss, M., Savithiri, S., Rajarajan, G., Thanikachalam, V., \&Saleem, H. (2015). Synthesis, spectroscopic (FT-IR, FT-Raman, $\mathrm{UV}$ and NMR) and computational studies on 3t-pentyl-2r, 6c diphenylpiperidin-4-one semicarbazone. Spectrochim. Acta Part A, 148, 189-202.https://doi.org/10.1016/j.saa.2015.03.117.

[20] Frisch, M.J., et. al., (2004). Gaussian 03, Revision C.02, Gaussian Inc., Wallinford, CT.

[21] Silverstein, R.M., \& Webster, F.X. (2005). Spectroscopic Identification of Organic Compounds, seventh ed., Wiley, New York.

[22] Kitson, R.E., \&Griffith, N.E. (1952). Infrared Absorption Band Due to Nitrile Stretching Vibration. Anal. Chem., 24: 334-337. https://doi.org/10.1021/ac60062a019.

[23] Savithiri, S., Arockia doss, M., Rajarajan, G., \& Thanikachalam, V. (2014). Synthesis, spectral, stereochemical, single crystal XRD and biological studies of 3t-pentyl-2r, 6c-diarylpiperidin-4-one picrate derivatives. J. Mol. Struct., 1075: 430-441. https://doi.org/10.1016/j.molstruc.2014.06.096.

[24] Evecen, M., Tanak, H., Tinmaz, F., Dege, N., \& OzerIlhan, I (2016).Experimental (XRD, IR and NMR) and theoretical investigations on 1-(2-nitrobenzoyl) 3, 5-bis (4 -methoxyphenyl)-4, 5dihydro-1 H-pyrazole. J. Mol. Struct., 1126, 117-126. https://doi.org/10.1016/j.molstruc.2016.01.069.

[25] Savithiri, S., Arockia doss, M., Rajarajan, G., Thanikachalam, V. Bharanidharan, \& S., Saleem, H. (2015). Spectroscopic (FT-IR, FTRaman) and quantum mechanical studies of 3t-pentyl-2r, 6cdiphenylpiperidin-4-one thiosemicarbazone. Spectrochim. Acta Part A, 136, 782-792.https://doi.org/10.1016/j.saa.2014.09.095.

[26] Savithiri, S., Arockia doss, M., Rajarajan, G., \&Thanikachalam, V. (2016). Molecular structure, vibrational spectral assignments (FTIR and FT-Raman), UV-Vis, NMR, NBO, HOMO-LUMO and NLO properties of 3t-pentyl-2r, 6c-diphenylpiperidin-4-one picrate based on DFT calculations.J. Mol. Struct., 1105, 225-237. https://doi.org/10.1016/i.molstruc.2015.10.063.

[27] Gorelsky, (2010). S.I.SWizard Program Revision 4.5, University of Ottawa, Ottawa, Canada.

[28] Omri, N., Yahyaoui, M., Banani, R., Messaoudi, S., Moussa, F., \&Abderrabba, M. (2016). Ab-initio HF and density functional theory investigations on the synthesis mechanism, conformational stability, molecular structure and UV spectrum of $\mathrm{N}^{\prime}$ Formylkynurenine. J. Theor. Comput. Chem., 15, 1650006. https://doi.org/10.1142/S0219633616500061.

[29] Kosar, B., \&Albayrak, C. (2011). Spectroscopic investigations and quantum chemical computational study of (E)-4-methoxy-2-[(ptolylimino) methyl] phenol, Spectrochim. Acta A,78, 160167.https://doi.org/10.1016/j.saa.2010.09.016.

[30] Bharathi, R., \&Santhi,N. (2017). Combined experimental and theoretical studies on molecular structures, spectroscopy of 4-(3-(2amino-3, 5-dibromophenyl)-1-(benzoyl)-4, 5-dihydro-1H-pyrazol5-yl)benzonitriles through NBO, FT-IR, HOMO-LUMO and NLO analyzes. J. Theor. Comput. https://doi.org/10.1142/S0219633617500572.

[31] Srinivasan, P., \& David Stephen, A. (2015). DFT and Bader's AIM analysis of 2, 5, diphenyl-1, 3, 4- oxadizole molecule: A organic 
light emitting diode (OLED). J. Theor. Comput. Chem., 14, 1550038. https://doi.org/10.1142/S0219633615500388.

[32] Zong-ming Jin, Weiqun Zhou, \& Zheng Jin. (1998). X-ray powder diffraction analysis of a nonlinear optical material 1 -benzoyl-3-(4benzyl)thiourea [N-benzoyl-N'-(4-benzyl)thiourea].J. Powder. Diff., 13, 41-43.https://doi.org/10.1017/S088571560000974X.

[33] Wei, M.X., Feng, L., Li, X.Q., Zhou, XZ, \&Sho, Z.H. (2009). Synthesis of new chiral 2, 5-disubstituted 1, 3, 4-thiadiazoles possessing $\gamma$-butenolide moiety and preliminary evaluation of in vitro anticancer activity.Eur. J. Med. Chem., 44, 3340-3344. https://doi.org/10.1016/j.ejmech.2009.03.023. 